\title{
Does Obesity Influence the Outcome of the Patients Following a Cardiac Arrest?
}

\author{
Mitul P Chavda ${ }^{1}$, Adrian Pakavakis ${ }^{2}$, David Ernest ${ }^{3}$
}

\begin{abstract}
Background: Obesity is one of the major risk factors for cardiovascular and peripheral vascular diseases. However, the obesity paradox confers survival benefits in heart failure and cardiac surgery patients. Studies examining the outcomes of obese patients following cardiac arrest provided conflicting results.

Objective: To study the association between obesity and outcome in patients following cardiac arrest.

Materials and methods: We conducted a retrospective cohort study at a tertiary intensive care unit (ICU). Data were collected from medical records between January 1, 2018 and December 31, 2018, for all adult ICU patients who were admitted to our ICU following a cardiac arrest. Data collected included demographics, anthropometrics, and details of the cardiac arrest. The primary outcome was survival to hospital discharge. Secondary outcomes were duration of mechanical ventilation, ICU, and hospital length of stay.

Results: A total of 126 patients were admitted to the ICU following a cardiac arrest during the study period, of whom 14 patients were excluded due to missing body mass index (BMI) data. Seventy-six patients were non-obese $(\mathrm{BMI}<30)$ and 36 patients were obese $(\mathrm{BMI} \geq 30)$. There was no difference in survival to hospital discharge between obese and non-obese patients ( $52.8 \mathrm{vs} 59.2 \%, p=0.52, \mathrm{OR}=0.77,95 \% \mathrm{Cl} 0.35-1.71$ ). Moreover, there was no difference between obese and non-obese patients in ICU length of stay (81.50 vs 76.0 hours, $p=0.42$ ), hospital length of stay ( 9 vs 10 days, $p=0.63$ ), and duration of mechanical ventilation ( 55 vs 43 hours, $p=0.30$ ). In the logistical regression analysis, BMI was not associated with improved survival ( $\mathrm{OR}=0.97,95 \% \mathrm{Cl} 0.92-1.03, p=0.23)$.

Conclusion: For patients admitted to ICU following cardiac arrest, we could not show that obesity improves survival, length of stay, or duration of mechanical ventilation.

Keywords: Body mass index, Cardiac arrest, Intensive care, Obesity.

Indian Journal of Critical Care Medicine (2020): 10.5005/jp-journals-10071-23665
\end{abstract}

\section{INTRODUCTION}

Out-of-hospital cardiac arrest is a leading cause of death, with an estimated 15,000 people suffering a cardiac arrest in Australia every year. ${ }^{1}$ Between $12 \%$ and $25 \%$ of out-of-hospital cardiac arrest, victims in Australia survive to hospital discharge. ${ }^{1}$ Recent Australian observational study by ANZ-CODE investigators showed that $26.3 \%$ of in-hospital cardiac arrest patients survive hospital discharge. ${ }^{2}$ Older age, cardiac arrest occurring at home, initial rhythm other than ventricular fibrillation and ventricular tachycardia, longer duration of no flow, longer duration of low flow, and treatment with adrenaline are known independent predictors of poor outcome after cardiac arrest. ${ }^{3}$

In recent times, obesity has emerged as one of the biggest health issues involving all age groups worldwide. It is one of the major risk factors for cardiovascular and peripheral vascular disease. However, obesity is associated with a lower mortality risk after cardiac surgery ${ }^{4}$ and with heart failure patients. ${ }^{5}$

Studies examining obese patients who suffered cardiac arrest provided conflicting results. ${ }^{6-10}$ The American Heart Association National Registry of Cardiopulmonary Resuscitation (NRCPR) demonstrated a higher rate of survival to discharge for overweight and obese patients compared with underweight and normal-weight patients with cardiac arrest caused by shockable rhythms. ${ }^{8}$ In contrast, body mass index (BMI) was not associated with in-hospital mortality in those who underwent extracorporeal cardiopulmonary resuscitation (ECPR). ${ }^{9}$ Body mass index $\geq 30 \mathrm{~kg} /$ $\mathrm{m}^{2}$ was shown to be a significant risk factor for mortality posttherapeutic hypothermia following cardiac arrest. ${ }^{10}$ Moreover,
${ }^{1}$ Department of ICCU, Flinders Medical Centre, Adelaide, South Australia, Australia

2,3 Department of ICU, Monash Medical Centre, Clayton, Victoria, Australia

Corresponding Author: Mitul P Chavda, Department of ICCU, Flinders Medical Centre, Adelaide, South Australia, Australia, Phone: +61449026671, e-mail: drmitulchavda@yahoo.com

How to cite this article: Chavda MP, Pakavakis A, Ernest D. Does Obesity Influence the Outcome of the Patients Following a Cardiac Arrest? Indian J Crit Care Med 2020;24(11):1077-1080.

Source of support: Nil

Conflict of interest: None

there is a lack of research on this topic from Australia. Therefore, we conducted this study to understand the association between obesity and mortality in patients following cardiac arrest.

\section{Materials and Methods}

\section{Study Design and Populations}

We performed a retrospective cohort study at a tertiary metropolitan intensive care unit (ICU) in Melbourne. Data were collected from medical records for all adults who were admitted to our ICU following in-hospital or out-of-hospital cardiac arrest between January 1, 2018 and December 31, 2018. We identified potential cases from our ICU's software program iCURE (Intensive Care Unit Reporting Excellence) and cross-checked with our clinical 
data manager. We filtered our search by using the keyword "cardiac arrest".

Body mass index was calculated by weight (in kilogram) divided by height (in meters) squared. The main source of height and weight was from the initial nutrition assessment form completed by our ICU dieticians. When not directly available, patient height was estimated using ulnar length. Patient weight was measured automatically by the patient's ICU beds (Hill Rom Progressa). The World Health Organization classification was used to categorize patients into under-weight (BMI <18.5), normal weight (BMI 18.5-24.9), overweight (BMI 25-29.9), class I obesity (BMI 30-34.9), class II obesity (BMI 35-39.9), and class III obesity $(\mathrm{BMI} \geq 40)^{11}$

We collected patients' data on demographics and anthropometrics, comorbidities, location of cardiac arrest, initial rhythm, the highest and lowest temperature in the first 24 hours of ICU admission, interventions (including a coronary angiogram, intra-aortic balloon pump, extracorporeal membrane oxygenation), duration of mechanical ventilation, ICU, and hospital length of stay. The primary outcome was survival to hospital discharge and the secondary outcomes were duration of mechanical ventilation, ICU, and hospital length of stay.

We conducted this observational study as a part of a quality assurance project and approval from our institutional Human Research and Ethics Committee was therefore not required.

\section{Statistical Analysis}

A comparison between groups was performed using completecase analysis. We used chi-square tests for categorical variables and Student's $t$-test or Mann-Whitney $U$ test for parametric and non-parametric variables. The relationship between BMI and survival was assessed using logistic regression. Continuous data are presented as means with standard deviations or medians with interquartile ranges as appropriate. Binary data are presented as proportions and comparisons presented as odds ratio (OR) with a 95\% confidence interval (Cl). Statistical analysis was performed using SPSS (Version 25, IBM Corporation). A two-tailed $p$ value $<0.05$ was considered statistically significant for all tests.

\section{Results}

A total of 126 patients were admitted to the ICU following in-hospital (38) or out-of-hospital (74) cardiac arrest, from which 14 patients were excluded because of missing BMI data. Out of 112 patients, 76 patients had calculated $\mathrm{BMI}<30$ and 36 patients had $\mathrm{BMI} \geq 30$.

The demographic characteristics of patients are summarized in Table 1. The mean age was similar between the two groups (61.7 vs 61.1 years). Both groups had more males than females. The obese (BMI $\geq 30$ ) group more commonly had diabetes (47 vs $32 \%$ ) and hypertension (61 vs 36\%).

There was no difference in the primary outcome of survival to hospital discharge between obese (BMI $\geq 30)$ and non-obese (BMI $<30$ ) groups ( 52.8 vs $59.2 \%, p=0.52, \mathrm{OR}=0.77,95 \% \mathrm{Cl} 0.35-1.71$; Table 2 and Fig. 1). There was no difference between non-obese and obese patients in ICU length of stay (76.0 vs 81.5 hours, $p=$ 0.42 ; Table 3 ), hospital length of stay (10 vs 9 days, $p=0.63$; Table 3 ), and duration of mechanical ventilation (43 vs 55 hours, $p=0.30$; Table 3).

On subgroup analysis, there was a trend toward better survival in non-obese patients who had initial shockable rhythm $(O R=0.39$, 95\% Cl 0.11-1.38, $p=0.15$; Table 4).
Table 1: Demographics

\begin{tabular}{|c|c|c|c|}
\hline & $\begin{array}{l}B M I<30 \\
(n=76)\end{array}$ & $\begin{array}{l}B M I \geq 30 \\
(n=36)\end{array}$ & $p$ value \\
\hline Age mean & $61.7 \pm 15.5$ & $61.1 \pm 10.8$ & 0.58 \\
\hline Male & $58(76 \%)$ & $24(66 \%)$ & 0.23 \\
\hline Diabetes & $24(32 \%)$ & $17(47 \%)$ & 0.12 \\
\hline Hypertension & $27(36 \%)$ & $22(61 \%)$ & 0.01 \\
\hline Previous $\mathrm{PCl}$ or $\mathrm{CABG}$ & $19(25 \%)$ & $10(28 \%)$ & 0.78 \\
\hline $\begin{array}{l}\text { Congestive heart } \\
\text { failure }\end{array}$ & $7(9 \%)$ & $5(14 \%)$ & 0.47 \\
\hline Atrial fibrillation & $10(13 \%)$ & $2(6 \%)$ & 0.22 \\
\hline PPM/AICD & $1(1 \%)$ & $1(3 \%)$ & 0.59 \\
\hline COPD & $11(14 \%)$ & $2(6 \%)$ & 0.16 \\
\hline Cirrhosis & $4(5 \%)$ & $1(3 \%)$ & 0.54 \\
\hline Dialysis dependent & $4(5 \%)$ & $0(0 \%)$ & 0.16 \\
\hline $\begin{array}{l}\text { Metastatic } \\
\text { malignancy }\end{array}$ & $1(1 \%)$ & $0(0 \%)$ & \\
\hline $\begin{array}{l}\text { Out-of-hospital } \\
\text { cardiac arrest }\end{array}$ & $52(68 \%)$ & $22(61 \%)$ & 0.39 \\
\hline $\begin{array}{l}\text { Initial shockable } \\
\text { rhythm }\end{array}$ & $35(46 \%)$ & $18(50 \%)$ & 0.37 \\
\hline
\end{tabular}

$A I C D$, automated intra-cardiac defibrillator; $B M I$, body mass index; $C A B G$, coronary artery bypass graft; COPD, chronic obstructive pulmonary disease; $\mathrm{PCl}$, percutaneous coronary intervention; PPM, permanent pacemaker

Table 2: Primary outcome: survival to hospital discharge

\begin{tabular}{llll}
\hline & Alive & Dead & Total \\
\hline $\mathrm{BMI} \geq 30$ & $19(52.8 \%)$ & $17(47.2 \%)$ & 36 \\
$\mathrm{BMI}<30$ & $45(59.2 \%)$ & $31(40.8 \%)$ & 76 \\
Total & $64(57.1 \%)$ & $48(42.9 \%)$ & 112
\end{tabular}

OR (odds ratio) for survival to hospital discharge for $\mathrm{BMI} \geq 30=0.77$ (95\% $\mathrm{Cl} 0.35-1.71)$

$p=0.52$

Chi-square test

$\mathrm{BMI}$, body mass index

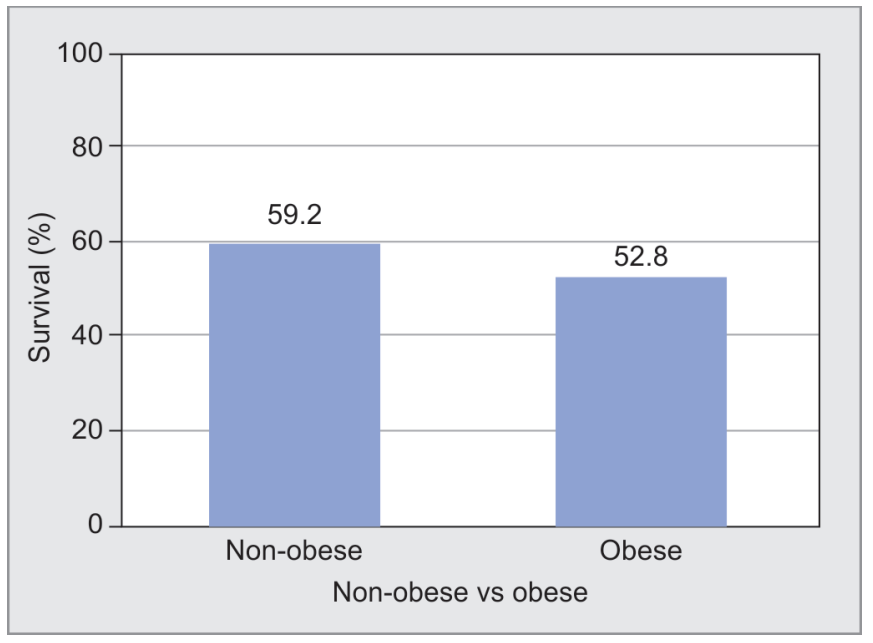

Fig. 1: Survival by obesity

In the logistical regression analysis, BMI was not associated with improved survival $(\mathrm{OR}=0.97,95 \% \mathrm{Cl} 0.92-1.03, p=0.23$, Table 5). There was a better survival with in-hospital cardiac arrest $(O R=2.94$, 
$95 \% \mathrm{Cl} 1.02-8.49, p=0.05)$ and initial shockable rhythm $(\mathrm{OR}=3.74$, $95 \% \mathrm{Cl} 0.94-14.82, p=0.06)$ independent of BMI.

\section{Discussion}

We could not show that obesity improves survival to hospital discharge among the patients admitted to the ICU following a cardiac arrest. Moreover, we found that obesity does not affect hospital or ICU length of stay or duration of mechanical ventilation.

There is an impression that obesity confers some survival advantages in heart failure and cardiac surgery. ${ }^{4-6,12}$ This inverse correlation between BMI and mortality is known as the obesity paradox. Greater metabolic reserve, younger age, and better cardioprotective medical therapy to obese patients are some hypotheses postulated for this phenomenon. Saba et al. showed that higher BMI is associated with lower all-cause mortality in the survivor of sudden cardiac arrest, suggesting the obesity paradox also applies to the post-cardiac arrest population. ${ }^{6}$ In contrast, a single-center trial by Breathett et al. demonstrated BMI $<30$ compared with $\mathrm{BMI} \geq 30$ was associated with better survival posthypothermia for cardiac arrest. ${ }^{9}$

In our study, we could not demonstrate that obesity confers survival benefit to patients who suffer cardiac arrest. We noted better survival to hospital discharge for the non-obese group. Although this difference was statistically non-significant, a $6.4 \%$ absolute difference in mortality in favor of non-obese can be clinically important. Possible explanations behind this observation

Table 3: Length of stay and duration of mechanical ventilation

\begin{tabular}{lccc}
\hline & $B M I<30$ & $B M I \geq 30$ & $p$ value \\
\hline ICU length of stay (in hours) & & & \\
$\quad$ Median & 76 & 81.5 & 0.42 \\
IQR & 99 & 165 & \\
Hospital length of stay (in days) & & & \\
$\quad$ Median & 10 & 9 & 0.64 \\
$\quad$ IQR & 13 & 10.8 & \\
$\begin{array}{l}\text { Duration of mechanical } \\
\text { ventilation (in hours) }\end{array}$ & & & \\
$\quad$ Median & & & \\
$\quad$ IQR & 43 & 55 & 0.30 \\
\hline
\end{tabular}

BMI, body mass index; IQR, interquartile range

Mann-Whitney $U$ test of statistical non-significance include unequal distribution of patient population between two groups, inadequate sample size, or the absence of any protective effect associated with obesity.

There are possible reasons which may account for reduced survival in patients with a high BMI following cardiac arrest. There is a potential role of visceral adipose tissue as a source of inflammation and promoter of atherosclerosis. ${ }^{13}$ The intra-abdominal and epicardial space are two compartments that contain visceral fats which are metabolically active and are the source of humoral and cellular inflammation in obese patients. These visceral fats secrete large numbers of cytokines and free fatty acids which have been associated with arrhythmias and sudden cardiac death. Moreover, it has been reported that sagittal abdominal diameter and waist-hip ratio are associated with an increased risk of sudden cardiac death independent of BMI. ${ }^{10,14}$

This study is the first trial from Australia to our knowledge which has explored the association between obesity and outcome following a cardiac arrest. This retrospective study was conducted in a major tertiary university teaching hospital that serves a large heterogeneous group of patients. We included all consecutive cardiac arrest patients without any selection to minimize bias and used objective clinical endpoints, such as, survival to hospital discharge, length of stay, and duration of mechanical ventilation as an outcome for our study.

There are several limitations to our study. It is a single-center and retrospective study. We excluded 14 (11\%) patients due to a lack of available measurements for either height or weight or both. We did not follow-up patients for a functional outcome, so it remains unknown whether the patient's BMI at the time of their cardiac arrest impacts their neurological or another recovery. In addition, given the retrospective nature of this study other anthropology measurements like sagittal abdominal diameter and waist-hip ratio were not collected.

Our study provides baseline data from an Australian center regarding outcomes following cardiac arrest in obese patients. Although our sample size was small and the difference between the two groups for the primary outcome was statistically nonsignificant, a $6.4 \%$ absolute difference in primary outcome in favor of non-obese can be important. If this difference is present, any future study would need approximately 1,880 patients (considering $80 \%$ study power and $\alpha=0.05$ ) and multicenter participation. Our study may inform future investigators who seek to undertake prospective studies in this area regarding the effects of obesity on hospital

Table 4: Outcome by initial rhythm and location of cardiac arrest

\begin{tabular}{|c|c|c|c|c|c|}
\hline & $B M I<30$ & $B M I \geq 30$ & $O R$ & $95 \% \mathrm{Cl}$ & $p$ value \\
\hline \multicolumn{6}{|c|}{ Shockable rhythm } \\
\hline Dead & $7(20 \%)$ & 7 (38.9\%) & 0.39 & $0.11-1.38$ & 0.15 \\
\hline Alive & $28(80 \%)$ & $11(61.1 \%)$ & & & \\
\hline \multicolumn{6}{|c|}{ Non-shockable rhythm } \\
\hline Dead & $24(58.5 \%)$ & $10(55.6 \%)$ & 1.13 & $0.37-3.46$ & 0.83 \\
\hline Alive & 17 (41.5\%) & $8(44.4 \%)$ & & & \\
\hline \multicolumn{6}{|c|}{ Out-of-hospital cardiac arrest } \\
\hline Dead & $21(40.1 \%)$ & $11(50 \%)$ & 0.68 & $0.25-1.84$ & 0.44 \\
\hline Alive & $31(59.6 \%)$ & $11(50 \%)$ & & & \\
\hline \multicolumn{6}{|c|}{ In-hospital cardiac arrest } \\
\hline Dead & $10(41.7 \%)$ & $6(42.9 \%)$ & 0.95 & $0.37-3.46$ & 0.94 \\
\hline Alive & $14(58.3 \%)$ & $8(57.1 \%)$ & & & \\
\hline
\end{tabular}

$\mathrm{Cl}$, confidence interval; $\mathrm{BMI}$, body mass index; $\mathrm{OR}$, odds ratio 
Table 5: Logistic regression

\begin{tabular}{|c|c|c|c|}
\hline \multicolumn{4}{|c|}{ (a) Unadjusted model } \\
\hline & OR of survival & $95 \% \mathrm{Cl}$ & $p$ value \\
\hline $\mathrm{BMI} \wedge$ & 0.97 & $0.93-1.01$ & 0.24 \\
\hline \multicolumn{4}{|c|}{ (b) Adjusted model } \\
\hline & OR of survival & $95 \% \mathrm{Cl}$ & $p$ value \\
\hline $\mathrm{BMI} \wedge$ & 0.97 & $0.92-1.03$ & 0.29 \\
\hline $\begin{array}{l}\text { Age at cardiac } \\
\text { arrest } \wedge\end{array}$ & 0.99 & $0.95-1.02$ & 0.52 \\
\hline Male sex & 1.16 & $0.45-3.03$ & 0.76 \\
\hline Location (IHCA) & 2.94 & $1.02-8.49$ & 0.05 \\
\hline Rhythm (VF)* & 3.74 & $0.94-14.82$ & 0.06 \\
\hline Rhythm (PEA)* & 0.48 & $0.12-1.87$ & 0.29 \\
\hline Diabetes & 0.82 & $0.32-2.11$ & 0.68 \\
\hline Hypertension & 0.68 & $0.26-1.77$ & 0.42 \\
\hline $\begin{array}{l}\text { History of } \mathrm{PCl} / \\
\text { CABG }\end{array}$ & 1.17 & $0.43-3.23$ & 0.76 \\
\hline
\end{tabular}

$\wedge$ as a continuous variable, ${ }^{*}$ Compared to asystole

$\mathrm{BMI}$, body mass index; $\mathrm{CABG}$, coronary artery bypass graft; $\mathrm{Cl}$, confidence interval; $\mathrm{IHCA}$, in-hospital cardiac arrest; $\mathrm{PCl}$, percutaneous coronary intervention; $\mathrm{PEA}$, pulseless electrical activity; VF, ventricular fibrillation

survival, length of stay, or duration of mechanical ventilation with regards to sample size determinations.

\section{Conclusion}

We could not show that obesity $(\mathrm{BMI} \geq 30)$ contributes to either a protective or harmful effect among the patients following either an in-hospital or out-of-hospital cardiac arrest. Further larger studies would be required to determine the impact of obesity on the outcome of patients following cardiac arrest.

\section{References}

1. Beck B, Bray J, Cameron P, Smith K, Walker T, Grantham H, et al. Regional variation in the characteristics, incidence and outcomes of out-of-hospital cardiac arrest in Australia and New Zealand: Results from the aus-ROC Epistry. Resuscitation 2018;126:49-57. DOI: 10.1016/j.resuscitation.2018.02.029.
2. The Australia and New Zealand Cardiac Arrest Outcome and Determinants of ECMO (ANZ-CODE) Investigators. The epidemiology of in-hospital cardiac arrests in Australia: a prospective multicentre observational study. Crit Care Resusc 2019;21(3):180-187.

3. Martinell L, Nielsen N, Herlitz J, Karlsson T, Horn J, Wise MP, et al. Early predictors of poor outcome after out-of-hospital cardiac arrest. Crit Care 2017;21(1):96. DOI: 10.1186/s13054-017-1677-2.

4. Mariscalco G, Wozniak MJ, Dawson AG, Serraino GF, Porter R, Nath $M$, et al. Body mass index and mortality among adults undergoing cardiac surgery. Circulation 2017;135(9):850-863. DOI: 10.1161/ CIRCULATIONAHA.116.022840.

5. Oreopoulos A, Padwal R, Kalantar-Zadeh K, Fonarow GC, Norris CM McAlister FA. Body mass index and mortality in heart failure: a metaanalysis. Am Heart J 2008;156(1):13-22. DOI: 10.1016/j.ahj.2008.02.014.

6. Matinrazm S, Ladejobi A, Pasupula DK, et al. Effect of body mass index on survival after sudden cardiac arrest. Clin Cardiol 2018;41(1):46-50. DOI: $10.1002 / c l c .22847$.

7. Stone P, Rizzolo K, Craig W, Pinz I, McCrum B, Qazi M, et al. Postresuscitation experience of obese and underweight patients after cardiac arrest. Chest 2017;152(4):A373. DOI: 10.1016/j. chest.2017.08.399.

8. Jain R, Nallamothu B, Chan P, American Heart Association National Registry of Cardiopulmonary Resuscitation (NRCPR) investigators Body mass index and survival after in-hospital cardiac arrest. Cir CardiovascQual Outcomes 2010;3:490-497.

9. Breathett K, Mehta N, Yildiz V, Abel E, Husa R. The impact of body mass index on patient survival after therapeutic hypothermia after resuscitation. Am J Emerg Med 2016;34(4):722-725. DOI: 10.1016/j. ajem.2015.12.077.

10. Adabag S, Huxley RR, Lopez FL, Chen LY, Sotoodehnia N, Siscovick D, et al. Obesity related risk of sudden cardiac death in the atherosclerosis risk in communities study. Heart 2014;101(3):215-221. DOI: 10.1136/ heartjnl-2014-306238.

11. International Obesity Task Force. Managing the Global Epidemic of Obesity. Report of the World Health Organization (WHO) Consultation on Obesity; June 5-7, 1997; Geneva, Switzerland.

12. Amundson D, Djurkovic $S$, Matwiyoff $G$. The obesity paradox. Crit Care Clin 2010;26(4):583-596. DOI: 10.1016/j.ccc.2010.06.004.

13. Alexopoulos N, Katritsis D, Raggi P. Visceral adipose tissue as a source of inflammation and promoter of atherosclerosis. Atherosclerosis 2014;233(1):104-112. DOI: 10.1016/j.atherosclerosis.2013. 12.023.

14. Empana JP, Ducimetiere $P$, Charles MA, Jouven X. Sagittal abdominal diameter and risk of sudden death in asymptomatic middle-aged men. The Paris prospective study I. ACC Curr J Rev 2005;14(3):46. DOI: 10.1016/j.accreview.2005.02.020. 